\title{
Pembelajaran Ketrampilan Komputer dan Teknologi Informasi (Microsoft Excel) bagi Tenaga Pengajar PAUD Pada Korwilcam Kecamatan Jambu
}

\author{
Aries Setiawan $^{* 1}$, Farrikh Al Zami ${ }^{2}$ \\ ${ }^{1}$ Teknik Informatika Fakultas Ilmu Komputer Universitas Dian Nuswantoro, ${ }^{2}$ Sistem Informasi \\ Fakultas Ilmu Komputer Universitas Dian Nuswantoro \\ e-mail: *1. arissetya.005@gmail.com, ${ }^{2}$ alzami@dsn.dinus.ac.id
}

\begin{abstract}
Abstrak
Tenaga pengajar PAUD memerlukan tingkat kualifikasi yang cukup tinggi, namun belum adanya dukungan terhadap kualifikasi tersebut, gambaran yang ada ditunjukkan dengan minimnya tingkat pendidikan tenaga pengajar, belum maksimalnya tingkat pelatihan yang diterima oleh tenaga pengajar PAUD serta tingkat penghasilan tenaga pengajar PAUD yang tidak memungkinkan untuk melakukan pengembangan diri dan ketrampilan, maka diperlukan mediator yang mampu menjembatani ilmu pengetahuan dan perkembangan teknologi dalam olah spreadsheet untuk membantu para tenaga pendidik dalam menyiapkan dokumen dan pelaporan yang lebih baik dan opotimal. Materi meliputi materi excel 1 meliputi operasi kalkulasi matematis (penjumlahan, pengurangan, perkalian, pembagian, serta variasinya), materi excel 2 meliputi operasi pengolahan data (mencari nilai maksimal, nilai minimum, nilai rata-rata, jumlah data) dan materi excel 3 (format isian, statistika dan grafik ). Hasil akhir pengabdian yang diperoleh adalah tenaga pengajar PAUD pada Korwilcam kecamatan Jambu mampu melakukan pengolahan data pendidikan dengan menggunakan Microsoft excel dengan menghemat waktu pengerjaan, rumus yang diterapkan mampu menyelesaian permasalahan perhitungan dan pengolahan data dengan cepat, dan tidak perlu dilakukan penyimpanan hasil pengerjaan dengan kertas kerja melainkan cukup disimpan dengan sebuah file yang tersimpan dalam direktori penyimpanan.
\end{abstract}

Kata kunci — tenaga pengajar PAUD, Microsoft excel, Korwilcam kecamatan Jambu

\begin{abstract}
PAUD teachers need a high level of qualification, but there is no support for these qualifications, the picture is shown by the lack of education level of the teaching staff, the level of training received by PAUD teaching staff and the level of income of PAUD teaching staff that is not possible to do self-development and skills, a mediator is needed who is able to bridge knowledge and technological developments in a spreadsheet to help educators prepare better and more optimal documents and reporting. The material includes excel 1 material covering mathematical calculation operations (addition, subtraction, multiplication, division, and variation), excel 2 material includes data processing operations (looking for maximum values, minimum values, average values, amount of data) and excel material 3 (formatting, statistics and graphics). The final result of the service obtained was PAUD teaching staff at the Korambu sub-district of Jambu able to process educational data by using Microsoft Excel by saving processing time, the formula applied was able to solve problems of data calculation and processing quickly, and no need to store the results of work with paperwork but simply save it with a file stored in the storage directory.
\end{abstract}

Keywords - PAUD teaching staff, Microsoft Excel, Korwilcam Jambu sub-district 


\section{PENDAHULUAN}

Pendidikan level dasar yang diterima oleh anak adalah Pendidikan anak usia dini (PAUD), pendidikan level ini sebagai langkah pembinaan yang ditujukan bagi anak usia 2 sampai menuju masa pendidikan taman kanak-kanak. Proses pendidikan ini adalah dengan memberikan rangsangan pertumbuhan dan perkembangan jasmani dan rohani agar anak memiliki kesiapan dalam memasuki pendidikan lebih lanjut, yang diselenggarakan pada jalur formal, nonformal, dan informal.

Diperlukan tenaga pengajar yang akan memberikan pendampingan anak dalam upaya menerima rangsangan pendidikan sehingga anak akan terarah dan dengan mudah dalam menerima asupan pendidikan. Tenaga pengajar harus memiliki tingkat pendidikan professional yang mampu menempatkan anak dalam upayanya memahami atau mencerna [1]].

Tenaga pengajar PAUD memerlukan tingkat kualifikasi yang cukup tinggi [2] , namun belum adanya dukungan terhadap kualifikasi tersebut, gambaran yang ada ditunjukkan dengan minimnya tingkat pendidikan tenaga pengajar, belum maksimalnya tingkat pelatihan yang diterima oleh tenaga pengajar PAUD serta tingkat penghasilan tenaga pengajar PAUD yang tidak memungkinkan untuk melakukan pengembangan diri dan ketrampilan [3] .

Beberapa upaya pemerintah meningkatkan kualitas guru sudah banyak dilakukan [4], diantaranya melalui pengadaan pelatihan dan workshop, yang penyelenggaraannya melalui Dinas Pendidikan Dasar serta perguruan tinggi yang menyelenggarakan program studi Pendidikan Guru PAUD. Namun program ini masih belum mampu menjangkau semua guru PAUD yang ada di berbagai wilayah

\section{METODE PENELITIAN}

Metode pelaksanaan dari kegiatan ini adalah dengan melakukan pelatihan berupa tutorial dimana tutor akan menjelaskan tentang perangkat lunak yang akan digunakan. Secara detail, pelaksanaan kegiatan pengabdian ini terdiri dari beberapa tahap. Berikut merupakan tahapan-tahapan yang dilakukan:

1. Melakukan koordinasi dengan pengurus PAUD Korwilcam Kec. Jambu selaku penanggung jawab agar pengabdian masyarakat berjalan tertib dan lancar.

2. Menentukan waktu dan tempat penyelenggaran pelatihan.

3. Perencanaan pelatihan yang disesuaikan jadwal dan ketersediaan jadwal para guru dan tutor.

4. Pemberitahuan kepada mitra. Informasi yang terkandung meliputi: tempat dan waktu pelaksanaan, serta agenda kegiatan.

5. Menyiapkan sarana dan prasarana kegiatan, laptop, laboratorium dan LCD.

6. Administrasi yang meliputi undangan peserta, surat menyurat, dokumentasi, daftar hadir untuk diarsip dan untuk pembuatan pelaporan.

7. Persiapan pembahasan rencana pelaksanaan pengabdian.

8. Penyiapan materi, berupa materi excel 1 meliputi operasi kalkulasi matematis (penjumlahan, pengurangan, perkalian, pembagian, serta variasinya), materi excel 2 meliputi operasi pengolahan data (mencari nilai maksimal, nilai minimum, nilai ratarata, jumlah data) dan materi excel 3 (format isian, statistika dan grafik) []․ 


\section{HASIL DAN PEMBAHASAN}

Beberapa contoh pembahasan yang diuraikan dalam pelaksanaan pengabdian untuk Tenaga Pengajar PAUD Pada Korwilcam Kecamatan Jambu yaitu

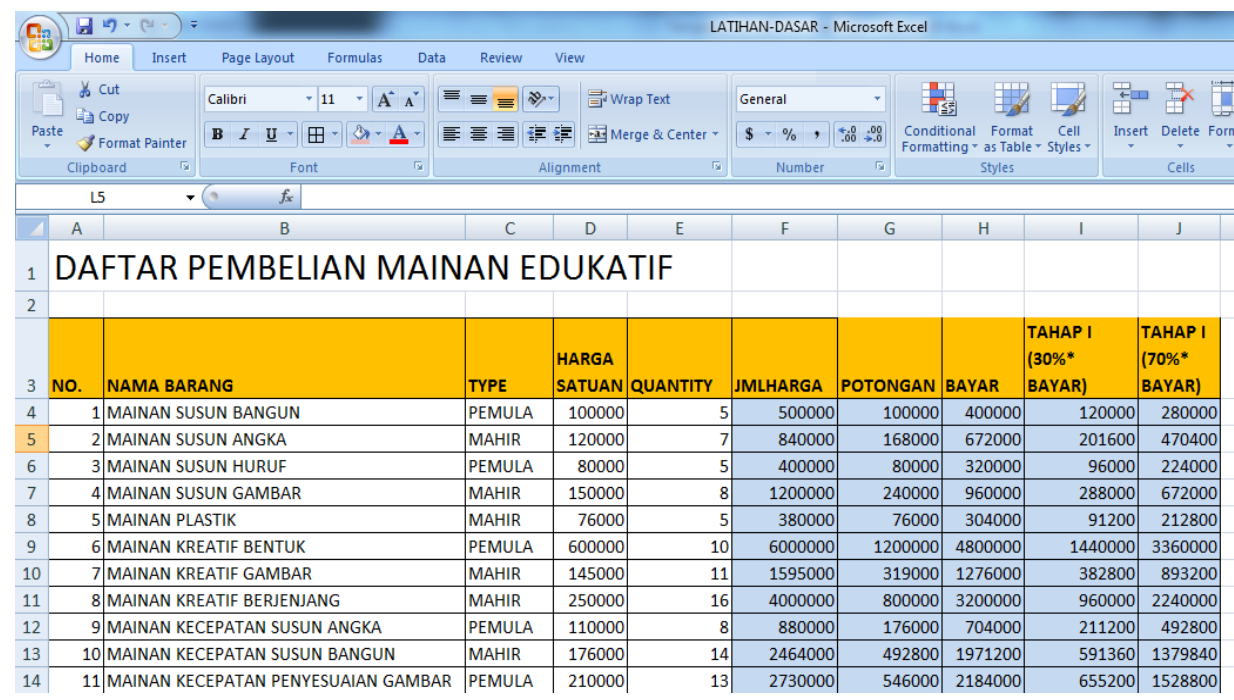

Gambar 1. Contoh materi excel 1

Pada gambar 1, bagian yang diblok biru merupakan kolom isian yang telah dihitung dengan rumus mengunakan fungsi penambahan, pengurangan dan perkalian

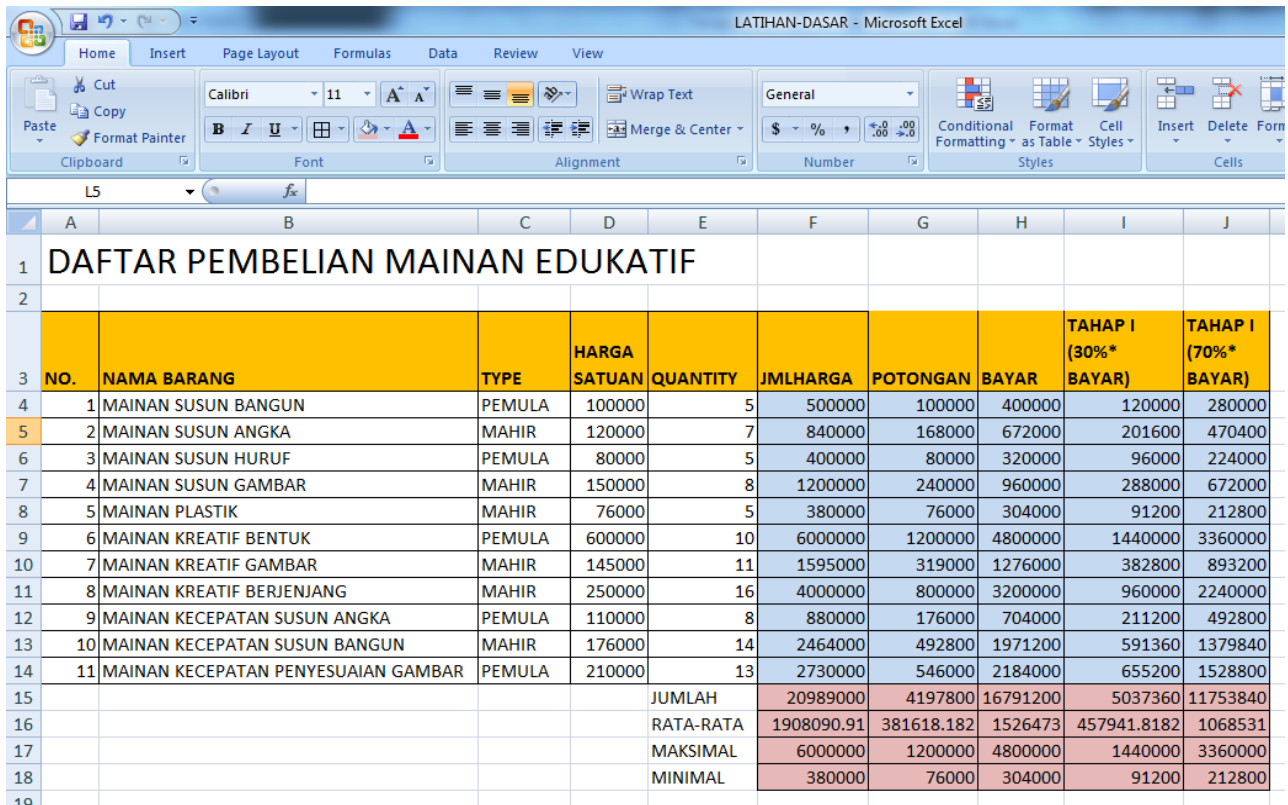

Gambar 2 . Contoh materi excel 2

Pada gambar 2, kolom isian dengan blok merah merupakan operasi menggunakan fungsi excel sum, averge, min dan max 


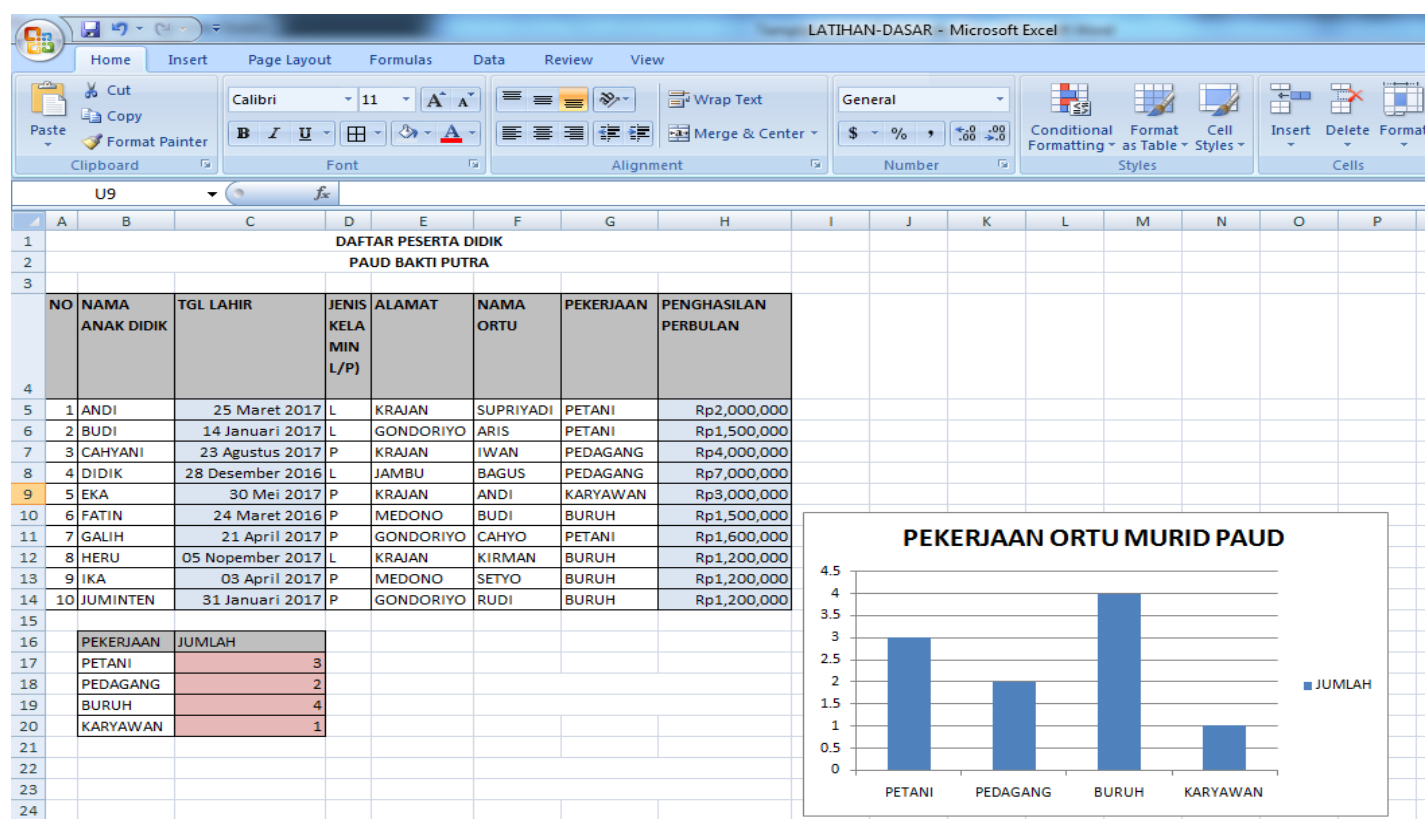

Gambar 3 . Contoh materi excel 3

Materi terakhir yang ditunjukkan pada gambar 3 merupakan unsur yang meliputi format tanggal, format angka, statistika pencarian jumlah siswa berdasarkan pekerjaan orang tua untuk kemudian dibuat sebuah grafik statistika

Tabel 1 Perbandingan Hasil Pengerjaan dengan cara manual dan fungsi

\begin{tabular}{|c|c|c|}
\hline Materi & \multicolumn{2}{|c|}{ Waktu } \\
\hline & Proses manual & Proses dengan fungsi excel \\
\hline Materi excel 1 & $>45$ menit & $<15$ menit \\
\hline Materi excel 2 & $>30$ menit & $<5$ menit \\
\hline Materi excel 3 & $>30$ menit & $<7$ menit \\
\hline
\end{tabular}

\section{KESIMPULAN}

Berdasarkan dari beberapa materi yang diberikan pada pengabdian masyarakat untuk Tenaga Pengajar PAUD Pada Korwilcam Kecamatan Jambu yang telah diuraikan pada bagian hasil dan pembahasan dapat diambil kesimpulan bahwa proses pengolahan data dengan menggunakan Microsoft excel mampu menghemat waktu pengerjaan, rumus yang diterapkan mampu menyelesaian permasalahan perhitungan dan pengolahan data dengan cepat, dan tidak perlu dilakukan penyimpanan hasil pengerjaan dengan kertas kerja melainkan cukup disimpan dengan sebuah file yang tersimpan dalam direktori penyimpanan.

\section{SARAN}

Tenaga Pengajar PAUD Pada Korwilcam Kecamatan Jambu dapat memulai beralih pengolahan data pendidikan dari proses manual menjadi proses komputer berbasis Microsoft excel untuk mengefektifkan aktivitas pngelolaan dan mengefisienkan waktu pengerjaan. 


\section{UCAPAN TERIMA KASIH}

Penulis mengucapkan terima kasih kepada Lembaga Penelitian dan Pengabdian Masyarakat (LPPM) Universitas Dian Nuswantoro yang telah memberikan dukungan melalui pendanaan serta kepada Korwilcam Kecamatan Jambu sebagai mitra dalam kegiatan pengabdian ini.

\section{DAFTAR PUSTAKA}

[1] Raihana, "Urgensi Sekolah PAUD Untuk Tumbuh Kembang Anak Usia Dini," Jurnal Pendidikan Islam Anak Usia Dini, 2018.

[2] Ristekdikti, "Panduan Bimbingan Teknis Dosen Matakuliah PAUD (Pendidikan Anak Usia Dini)," 2018.

[3] Undang-Undang RI No. 14 tentang Guru dan Dosen, 2005.

[4] Dian Mahsunah, "Kebijkan Pengembangan Profesi Guru," 2012.

[5] Benny A. Pribadi, Komputer Dalam Kegiatan. Pengembangan. Anak Usia Dini.: Universitas Terbuka, 2012. 